\title{
Preferensi Sumber Informasi Inovasi Pengolahan Kotoran Ternak Menjadi Kompos pada Kelompok Peternak Sapi Potong di Kabupaten Bantul
}

\author{
Emiliana Anggriyani $^{1}$, F. Trisakti Haryadi ${ }^{2}$ dan Suharjono Triatmojo ${ }^{2}$ \\ ${ }^{1}$ Pascasarjana Fakultas Peternakan, Universitas Gadjah Mada Yogyakarta \\ Jl. Fauna No. 3, Bulaksumur, Yogyakarta, 55281 \\ ${ }^{2}$ Fakultas Peternakan, Universitas Gadjah Mada Yogyakarta \\ Jl. Fauna No. 3, Bulaksumur, Yogyakarta, 55281 \\ Email: emiliana.anggry@gmail.com
}

\begin{abstract}
ABSTRAK
Penelitian ini bertujuan untuk menganalisis sumber informasi inovasi peternak dalam pengolahan kotoran ternak menjadi kompos. Materi yang digunakan dalam penelitian ini adalah semua anggota dari dua kelompok peternak sapi potong (sebagai sistem) yakni Kelompok Sido Rejo dan Kelompok Sido Mulyo di Kabupaten Bantul yang pernah memperoleh informasi mengenai inovasi kompos. Metode pengambilan data dilakukan dengan sensus melalui wawancara kepada peternak. Sumber informasi inovasi dianalisis secara deskriptif. Hasil penelitian menunjukkan bahwa sebagian besar responden baik Kelompok Sido Rejo maupun Sido Mulyo memilih sumber informasi personal. Kesimpulan dari penelitian ini yaitu sumber informasi personal lebih disukai oleh baik Kelompok Sido Rejo maupun Kelompok Sido Mulyo.
\end{abstract}

Kata kunci: preferensi, sumber informasi, inovasi, kompos

\section{Information Sources Preference of Innovation in Manure Processing of Beef Cattle Farmers Groups in Bantul}

\begin{abstract}
The aim of this study was to analyze the sources of information of innovation in processing manure into compost. The respondents used in this study were the members of Sido Rejo and Sido Mulyo groups in Bantul who had already obtained information about the innovation of compost. This research was conducted by census through interviews of the object of research to obtain primary data. The preference of the information source of compost innovation was analyzed by descriptive method. The results of the research showed that most respondents from Sido Rejo and Sido Mulyo group preferred the personal information source. The study came to a conclusion that the personal information source was preferred by most respondents from Sido Rejo and Sido Mulyo groups.
\end{abstract}

Key words: preference, source of information, innovation, compost 


\section{PENDAHULUAN}

Penggunaan pupuk kimia yang berlebihan selama kurun waktu yang lama menyebabkan tanah menjadi semakin kritis dan gersang. Hal ini dapat ditanggulangi salah satunya dengan mengurangi penggunaan pupuk kimia dan beralih pada pupuk organik.

Pupuk organik dapat dibuat dari kotoran ternak. Sebagian peternak membiarkan kotoran sapi potong hanya ditumpuk atau dibiarkan saja. Kotoran yang tidak diolah dan langsung digunakan untuk memupuk tanaman akan sangat berbahaya dan dapat meracuni tanaman karena menghasilkan panas yang merupakan hasil perombakan bahan organik dan dihasilkan asam organik yang beracun yang dapat menghambat pertumbuhan tanaman. Oleh karena itu kotoran sapi potong akan lebih baik apabila diolah dahulu menjadi kompos sehingga unsur haranya dapat dimanfaatkan oleh tanaman, disamping itu panas dan racun telah hilang selama proses pengomposan.

Pengenalan inovasi kompos dapat melalui berbagai macam saluran komunikasi. Soekartawi (2005) menyatakan bahwa kajian komunikasi pertanian dan pembangunan dalam bidang pertanian perlu mendapat tempat tersendiri. Komunikasi pertanian adalah suatu pernyataan antar manusia yang berkaitan dengan kegiatan di bidang pertanian, baik secara perorangan atau berkelompok yang sifatnya umum menggunakan lambang-lambang tertentu.

Komunikasi pertanian sangat penting guna menunjang penyerapan informasi dari penyuluh, sehingga pesan yang disampaikan penyuluh dapat diterima dan diterapkan dengan baik dan benar. Akan tetapi yang terjadi saat ini tidak semua teknologi baru yang ditawarkan oleh pihak penyuluh mampu diserap dan diadopsi oleh peternak. Van Den Ban (1999) menyatakan tujuan utama kebijakan pembangunan pertanian yakni merangsang petani untuk memanfaatkan teknologi produksi modern dan ilmiah yang dikembangkan melalui penelitian.
Penyuluhan diantaranya merupakan proses untuk 1) meningkatkan pengetahuan dan mengembangkan wawasan terhadap suatu masalah, serta membantu menyusun kerangka berdasarkan pengetahuan yang dimiliki petani, 2) membantu petani memperoleh pengetahuan yang khusus berkaitan dengan cara pemecahan masalah yang dihadapi serta akibat yang ditimbulkannya sehingga mereka mempunyai berbagai alternatif tindakan (Van Den Ban, 1999).

Setiap peternak dengan latar belakang yang berbeda-beda memiliki preferensi sumber informasi yang berbeda-beda dalam memperoleh inovasi. Berbagai macam sumber informasi pertanian tersedia diantaranya yaitu melalui majalah pertanian, televisi, radio, hasil penelitian, dan sumber personal. Akan tetapi karena minimnya akses peternak dan kurangnya publikasi ke masyarakat maka hanya sedikit sumber informasi yang mampu diakses peternak.

Inovasi mengenai pengolahan kotoran ternak dengan pembuatan kompos telah diperkenalkan pada kelompok peternak di Kabupaten Bantul, terlebih adanya peraturan dari Pemerintah Daerah Bantul bahwa tidak ada kotoran ternak yang keluar Bantul tetapi harus dimanfaatkan sendiri. Hal tersebut dimaksudkan untuk memperbaiki lahan pertanian dan meningkatkan sistem pertanian organik di daerah Bantul. Program yang dicanangkan tersebut tidak sepenuhnya berjalan, banyak peternak tidak menerapkan pengolahan kotoran ternak tersebut. Oleh karena itu penelitian ini bermaksud untuk menjawab pertanyaan bagaimanakah sumber informasi inovasi peternak dalam pengolahan kotoran ternak menjadi kompos. Penelitian ini bertujuan untuk menganalisis sumber informasi inovasi peternak dalam pengolahan kotoran ternak menjadi kompos.

\section{MATERI DAN METODE}

Penelitian ini dilaksanakan pada kelompok peternak sapi potong Kelompok Sido Rejo, Patalan, Jetis, Bantul dan Kelompok Sido Mulyo, Segoroyoso, Pleret, 
Bantul. Penelitian ini dilakukan pada Bulan September 2011 sampai November 2011. Sumber informasi berasal dari peternak kedua kelompok tersebut. Pengumpulan data primer dilakukan dengan kuesioner.

\section{Penentuan Responden}

Penentuan responden penelitian dengan metode sensus yaitu mengambil semua anggota Kelompok Sido Rejo dan Sido Mulyo di Kabupaten Bantul untuk menggambarkan masing-masing sistem kelompok peternak. Kedua kelompok tersebut dipilih karena berdiri pada tahun yang berbeda sehingga tergolong kelompok yang relatif lama (18 tahun) dan baru (7 tahun), serta pernah mendapat informasi mengenai inovasi pembuatan kompos dari pihak penyuluh atau pihak luar baik secara penjelasan maupun demonstrasi teknis.

\section{Macam dan Proses Pengambilan Data}

Data primer diperoleh langsung dari peternak melalui wawancara terstruktur dengan menggunakan kuesioner dan pengamatan langsung. Data yang diambil meliputi identitas responden, pengalaman beternak, lama menjadi anggota kelompok, tingkat kosmopolitan, sumber informasi personal dan non personal. Data sekunder diperoleh dari Dinas Pertanian Kabupaten Bantul dan dinas terkait.

\section{Pengukuran Variabel}

Sumber informasi responden terhadap informasi inovasi kompos dianalisis secara deskriptif.

\section{HASIL DAN PEMBAHASAN}

\section{Keadaan Kelompok Peternak Responden}

\section{Keadaan Kelompok Sido Rejo}

Kelompok Sido Rejo adalah kelompok peternak sapi potong yang terletak di dusun Sulang Kidul, Patalan, Jetis, Bantul dan berdiri pada tahun 1994. Berawal dari adanya anjuran dari Dinas untuk menjaga lingkungan tempat tinggal. Akibat anjuran tersebut maka ternak-ternak yang awalnya dipelihara di sekitar rumah, dipindahkan dan dikelompokkan ke lahan tersendiri milik desa. Kelompok terus berkembang sampai saat ini dan telah memperoleh banyak penghargaan serta mampu memperoleh bantuan dari Jamsostek sehingga mempunyai bangunan kandang yang baik dan lingkungan kandang yang cukup bersih dan tertata rapi.

Peternak harus membayar sewa kavling sebesar Rp. 27.500/kavling/tahun ke pemerintah desa. Lahan HMT yang dimiliki seluas 0,5 Ha. Saat ini jumlah anggota mencapai 46 orang yang diketuai oleh Bapak H. Slamet Pujoharjono. Bapak H. Slamet Pujoharjono dibantu oleh beberapa pengurus yang mampu mengelola kelompok agar berjalan lebih baik. Kelompok mengadakan pertemuan setiap malam Rabu Kliwon. Kegiatan ronda di kelompok juga sudah berjalan, bahkan sudah terdapat jadwal ronda setiap malam untuk menjaga keamanan lingkungan kandang. Kelompok telah memiliki berbagai fasilitas yang memadai. Kelompok memiliki bangunan kandang yang relatif baik dilihat dari bahan bangunan dan tata letak kandang, selain itu juga memiliki ruang pertemuan, biogas yang telah mampu digunakan untuk memasak, serta adanya tempat untuk menampung kompos yang telah jadi.

\section{Keadaan Kelompok Sido Mulyo}

Kelompok Sido Mulyo berdiri pada tahun 2005, beranggotakan masyarakat Dusun Segorosoyo II dan daerah sekitarnya, yang bertujuan meningkatkan pendapatan warga dan sebagai pelaku pembangunan Dusun Segoroyoso II dan masyarakat luas pada umumnya. Kelompok beranggotakan 60 orang dengan ketua Bapak Ismu Wibowo.

Kelompok mengadakan pertemuan setiap malam minggu kliwon, akan tetapi saat ini relatif jarang dilakukan. Sewa kandang sebesar Rp33.000/kavling/tahun, pembayaran dilakukan dua tahun sekali. 
Tabel 1. Karakteristik responden Kelompok Sido Rejo dan Sido Mulyo

\begin{tabular}{|c|c|c|c|}
\hline \multirow[t]{2}{*}{ Karakteristik responden } & \multicolumn{2}{|c|}{ Kelompok ternak } & \multirow[t]{2}{*}{ Probability } \\
\hline & Sido Rejo & Sido Mulyo & \\
\hline Rata-rata umur (tahun) & $49,35 \pm 11,7$ & $46,63 \pm 12,58$ & 0,36 \\
\hline Tingkat pendidikan (\%) & & & $0,00^{* *}$ \\
\hline$<\mathrm{SMP}$ & 41,37 & 68,33 & \\
\hline SMP & 19,57 & 20,00 & \\
\hline SMA & 21,74 & 11,67 & \\
\hline$>$ SMA & 17,39 & 0 & \\
\hline Pekerjaan utama & & & $0,05^{*}$ \\
\hline Petani & 63,04 & 80 & \\
\hline Bukan petani & 36,96 & 20 & \\
\hline Rata-rata pengalaman beternak (tahun) & $18,25 \pm 13,61$ & $23,15 \pm 15,73$ & 0,17 \\
\hline $\begin{array}{l}\text { Rata-rata lama menjadi anggota } \\
\text { kelompok (tahun) }\end{array}$ & $12,23 \pm 6,47$ & $5,72 \pm 0,88$ & $0,00^{*}$ \\
\hline Tingkat kosmopolitan (\%) & & & 0,27 \\
\hline Rendah & 93,48 & 98,33 & \\
\hline Tinggi & 6,52 & 1,67 & \\
\hline Rata-rata luas lahan pertanian (Ha) & $1,33 \pm 1,69$ & $0,26 \pm 0,45$ & $0,00^{* *}$ \\
\hline Rata-rata jumlah kepemilikan sapi (UT) & $1,31 \pm 0,79$ & $0,99 \pm 0,71$ & 0,19 \\
\hline
\end{tabular}

Lahan HMT yang dimiliki kelompok sebesar 2500 m. Bahan bangunan Kandang Kelompok Sido Mulyo masih terlihat sederhana dibanding Kelompok Sido Rejo. Kelompok ini juga belum memiliki ruang pertemuan yang cukup memadai, akan tetapi telah memiliki tempat untuk membuat kompos. Fasilitas di Kelompok Sido Mulyo masih relatif kurang memadai dibanding Kelompok Sido Mulyo karena Kelompok Sido Mulyo yang relatif baru.

\section{Karakteristik Responden}

Responden merupakan peternak anggota pada Kelompok Sido Rejo, Patalan, Kecamatan Jetis, dan Kelompok Sido Mulyo, Segoroyoso, Kecamatan Pleret, Kabupaten Bantul masing-masing berjumlah 46 orang dan 60 orang. Karakteristik responden dalam penelitian meliputi umur, tingkat pendidikan, perkerjaan utama, pengalaman beternak, lama menjadi anggota kelompok, tingkat kosmopolitan, rata-rata luas lahan pertanian yang dimiliki, dan jumlah ternak yang dimiliki.
Tabel 1 menunjukkan bahwa terdapat perbedaan tingkat pendidikan, pekerjaan utama, lama menjadi anggota kelompok dan rata-rata luas lahan pertanian antar kelompok. Peternak Kelompok Sido Rejo memiliki pendidikan yang relatif lebih tinggi dari Kelompok Sido Mulyo. Tingkat pendidikan untuk Kelompok Sido Rejo sebanyak 41,37\% peternak menempuh kurang dari wajib belajar 9 tahun, sedangkan Kelompok Sido Mulyo sebagian besar peternak berpendidikan kurang dari SMP (68,33\%). Pekerjaan utama sebagai petani di Kelompok Sido Mulyo lebih tinggi dari Kelompok Sido Rejo.

Kelompok Sido Rejo lebih lama berdiri sebagai kelompok peternak dibanding Kelompok Sido Mulyo, sebagian besar anggota masing-masing kelompok masuk menjadi anggota kelompok sejak awal kelompok tersebut berdiri. Kepemilikan lahan pertanian di Kelompok Sido Rejo lebih luas dari Kelompok Sido Mulyo. Penguasaan lahan pertanian responden Kelompok Sido Rejo lebih luas dibanding responden Kelompok Sido 
Tabel 2. Sumber informasi yang diterima responden mengenai inovasi pengolahan kotoran ternak menjadi kompos ${ }^{\mathrm{a}}$

\begin{tabular}{|c|c|c|c|c|}
\hline \multirow[t]{2}{*}{ Sumber Informasi } & \multicolumn{2}{|c|}{ Kelompok Sido Rejo $^{b}$} & \multicolumn{2}{|c|}{ Kelompok Sido Mulyo $^{\mathrm{C}}$} \\
\hline & $\begin{array}{l}\text { Jumlah } \\
\text { responden }\end{array}$ & $\begin{array}{l}\text { Persentase } \\
\text { (\%) }\end{array}$ & $\begin{array}{l}\text { Jumlah } \\
\text { responden }\end{array}$ & $\begin{array}{l}\text { Persentase } \\
\text { (\%) }\end{array}$ \\
\hline Personal & & & & \\
\hline Penyuluh & 41 & 89,13 & 14 & 23,33 \\
\hline Sesama peternak & 35 & 76,09 & 55 & 91,67 \\
\hline $\begin{array}{l}\text { Peternak lain } \\
\text { kelompok }\end{array}$ & 0 & 0 & 0 & 0 \\
\hline Non personal & & & & \\
\hline Majalah pertanian & 0 & 0 & 0 & 0 \\
\hline Koran & 1 & 2,17 & 1 & 1,67 \\
\hline Radio & 22 & 47,83 & 0 & 0 \\
\hline Televisi & 8 & 17,39 & 0 & 0 \\
\hline Brosur & 33 & 71,74 & 3 & 5,00 \\
\hline
\end{tabular}

Mulyo, hal ini memungkinkan kelompok Sido Rejo membutuhkan lebih banyak pupuk dalam hal ini kompos untuk memupuk lahan pertanian mereka.

Rata-rata umur, rata-rata pengalaman beternak, tingkat kosmopolitan, status sosial dan rata-rata kepemilikan jumlah ternak antara kedua kelompok tersebut tidak berbeda secara signifikan (Tabel 1).

\section{Sumber Informasi Inovasi Pengolahan Kotoran Ternak Menjadi Kompos}

Sumber informasi inovasi pengolahan kotoran ternak menjadi kompos dapat secara personal maupun non personal. Sumber informasi inovasi personal merupakan sumber informasi melalui tatap muka sedangkan non personal tanpa tatap muka.

\section{Penggunaan sumber informasi inovasi}

Responden baik Kelompok Sido Rejo maupun Sido Mulyo telah menerima berbagai macam sumber informasi mengenai inovasi pengolahan kotoran ternak menjadi kompos. Masing-masing responden menerima beragam sumber informasi mengenai inovasi pengolahan kotoran ternak menjadi kompos dapat dilihat pada Tabel 2.
Tabel 2 menunjukkan bahwa sebanyak 89,13\% responden Kelompok Sido Rejo pernah menerima sumber informasi inovasi pengolahan kotoran ternak menjadi kompos secara personal dari penyuluh dan 76,09\% dari sesama peternak dalam 1 kelompok. Sumber non personal melalui brosur diterima sebanyak $71,74 \%$ responden Kelompok Sido Rejo. Hal ini menunjukkan Kelompok Sido Rejo relatif terbuka terhadap sumber informasi baik personal maupun non personal, akan tetapi sumber informasi non personal yang diterima kurang beragam.

Kelompok Sido Mulyo sebanyak 91,67\% responden pernah menerima sumber informasi inovasi kompos dari sesama peternak 1 kelompok, dan hanya 5\% responden menerima sumber informasi inovasi melalui sumber non personal berupa brosur (Tabel 2). Hal tersebut dapat menunjukkan bahwa responden Kelompok Sido Mulyo kurang menerima sumber informasi inovasi non personal. Akses responden Kelompok Sido Mulyo terhadap media non personal masih terbatas. Sosialisasi inovasi pengolahan kotoran ternak menjadi kompos terhadap semua anggota Kelompok Sido Mulyo dari pihak penyuluh terkait juga masih rendah. 
Tabel 3. Preferensi sumber informasi inovasi responden

\begin{tabular}{|c|c|c|c|c|}
\hline \multirow[t]{2}{*}{ Sumber Informasi } & \multicolumn{2}{|c|}{ Kelompok Sido Rejo } & \multicolumn{2}{|c|}{ Kelompok Sido Mulyo } \\
\hline & $\begin{array}{l}\text { Jumlah } \\
\text { responden }\end{array}$ & $\begin{array}{c}\text { Persentase } \\
\text { (\%) }\end{array}$ & $\begin{array}{l}\text { Jumlah } \\
\text { responden }\end{array}$ & Persentase (\%) \\
\hline Personal & 43 & 93,48 & 60 & 100,00 \\
\hline Penyuluh & 11 & 23,91 & 60 & 100,00 \\
\hline Sesama peternak & 32 & 69,57 & 0 & 0 \\
\hline Non Pesonal & 3 & 6,52 & 0 & 0 \\
\hline Brosur & 2 & 4,35 & & \\
\hline Televisi & 1 & 2,17 & & \\
\hline Total & 46 & 100,00 & 60 & 100,00 \\
\hline
\end{tabular}

Kelompok Sido Mulyo yang relatif baru sebagai suatu kelompok ternak tentunya masih banyak membutuhkan informasiinformasi dari pihak-pihak terkait.

Bulu et al. (2009) menyatakan akses informasi dan frekuensi komunikasi inovasi melalui media cetak dan audio visual yang relatif rendah disebabkan oleh beberapa hal antara lain : 1) terbatasnya media cetak yang dapat diakses petani, 2) petani kurang tertarik dengan media cetak karena sulit dipahami, 3) sebagian besar petani tidak bisa baca, 4) terbatasnya informasi inovasi yang disampaikan melalui media audio visual (televisi dan radio), dan 5) media audio visual lebih banyak dimanfaatkan petani sebagai media hiburan.

Rendahnya modal intelektual (pendidikan) petani membuat akses petani terhadap sumber informasi menjadi lemah sehingga mereka terisolasi dari informasi dan membuat mereka lebih banyak menunggu informasi karena merasa agak sulit akses terhadap informasi yang dibutuhkannya. Petani memperoleh informasi dari sumber informasi kedua yaitu sesama petani (Tamba dan Sarma, 2007).

\section{Preferensi sumber informasi inovasi pengolahan kotoran ternak menjadi kompos}

Sumber informasi yang disukai peternak dalam penelitian ini dibedakan menjadi sumber informasi personal atau tatap muka dan sumber informasi non personal atau non tatap muka.
Sumber informasi personal disukai oleh 93,48\% responden Kelompok Sido Rejo (Tabel 3). Sumber personal yang paling disukai tersebut adalah dari peternak 1 kelompok. 6,52\% responden menyukai sumber informasi non personal yakni brosur dan televisi. Hal tersebut menunjukkan bahwa para anggota Kelompok Sido Rejo mempercayai sesama peternak (dalam satu kelompok) sebagai sumber informasi inovasi kompos, tidak hanya mengandalkan penyuluh. Lama berdiri sebagai kelompok ternak membuat kelompok ini memiliki kemandirian, karena telah banyaknya pengalaman dan informasi yang diterima.

Seluruh responden (100\%) Kelompok Sido Mulyo lebih menyukai sumber informasi personal, yaitu dari pihak penyuluh. Hal ini menunjukkan bahwa responden pada Kelompok Sido Mulyo masih sangat membutuhkan pendampingan tatap muka dari pihak penyuluh terhadap pembuatan kompos agar mereka dapat lebih jelas dalam proses pembuatan kompos, tidak hanya terbatas pada kalangan pengurus saja. Sebagian besar responden Kelompok Sido Mulyo selama ini hanya menerima informasi dari sesama peternak (Tabel 2), padahal sebagai kelompok yang relatif baru responden masih membutuhkan informasi dari pihak luar yang dapat dipercaya. Hal ini juga berkaitan dengan tingkat kemandirian kelompok yang masih rendah. Mereka lebih yakin dan jelas apabila langsung mendapat pengarahan dan praktek dari pihak luar dalam hal ini penyuluh. Hal ini sesuai 
dengan pendapat Okwu dan Shimayohol (2011) bahwa responden lebih memilih agen penyuluh pada posisi pertama sebagai sumber informasi yang paling disukai, kemudian posisi selanjutnya radio, tetangga dan televisi. Koran menjadi pilihan terakhir sebagai sumber informasi yang dipilih. Penyuluh dipilih sebagai sumber informasi yang paling disukai mungkin dikaitkan adanya interaksi interpersonal dan umpan balik yang disukai petani.

Villamil et al. (2008) menyatakan bahwa lebih dari $65 \%$ petani responden secara berturut-turut memilih pihak dinas pertanian, brosur, petani lain dan petani tetangga, internet dan koran sebagai 5 sumber yang paling disukai petani sebagai sumber informasi teknologi. Hal tersebut menunjukkan bahwa petani lebih menyukai sumber informasi personal dalam mencari informasi pertanian.

\section{KESIMPULAN}

Kelompok Sido Rejo maupun Kelompok Sido Mulyo sebagian besar lebih menyukai sumber informasi personal sebagai sumber informasi inovasi kompos.

\section{DAFTAR PUSTAKA}

Bulu, Y.G., S. S. Hariadi, A. S. Herianto, Mudiyono. 2009. Pengaruh Modal Sosial Dan Keterdedahan Informasi Inovasi terhadap Tingkat Adopsi Inovasi Jagung Di Kabupaten Lombok Timur Nusa Tenggara Barat. Jurnal Agro Ekonomi, 27: 1 - 21. Balai Pengkajian Teknologi Pertanian NTB.

Okwu,O.J., and D. Shimayohol. 2011. Extension Communication Channels' Usage And Preference By Farmers In Benue State, Nigeria. Journal of Agricultural Extension And Rural Development.3: 88-94.

Soekartawi. 2005. Prinsip Dasar Komunikasi Pertanian. UI Press. Jakarta.

Tamba, M dan M.Sarma. 2007. Faktor-Faktor Yang Mempengaruhi Kebutuhan Informasi Pertanian Bagi Petani Sayuran Di Provinsi Jawa Barat. Jurnal Penyuluhan. Vo. 3 No. 1. Institut Pertanian Bogor.

Van Den Ban dan Hawkins. 1999. Penyuluhan Pertanian. Kanisius. Yogyakarta.

Villamil, M.B., A.H.Silvis, and G.A.Bollero. 2008. Potencial Micanthus' Adoption In Illinois : Information Needs And Preferred Information Channels. Journal Of Biomass And Bioenergy 32 (2008) 1338-1348. 